\title{
Publisher Correction: Asymmetric opening of HIV-1 Env bound to CD4 and a coreceptor-mimicking antibody
}

Zhi Yang, Haoqing Wang, Albert Z. Liu(D, Harry B. Gristick and Pamela J. Bjorkman (1)

Correction to: Nature Structural \& Molecular Biology https://doi.org/10.1038/s41594-019-0344-5, published online 2 December 2019. In the version of this article initially published, in Fig. $6 \mathrm{c}, \mathrm{d}$ the labels for the $\beta$-strands $\beta 2$ and $\beta 3$ were transposed. The error has been corrected in the HTML and PDF versions of the article.

Published online: 16 December 2019

https://doi.org/10.1038/s41594-019-0362-3

(c) The Author(s), under exclusive licence to Springer Nature America, Inc. 2019 